\title{
Investigating Total Entrepreneurial Activity and Entrepreneurial Intention in Africa Regions using Fuzzy-Set Qualitative Comparative Analysis (fsQCA)
}

\begin{abstract}
This study offers a novel evaluation of the conditions for Total Entrpreneurial Activity (TEA) and Entrepreneurial Intention (EI) across 59 Sub-Saharan African regions. The analysis employs fuzzy-set Qualitative Comparative Analysis using Global Entrepreneurship Monitor (2013) survey data using five condition variables, measuring regional-level entrepreneurial attitudes and perceptions, including education level, considered against TEA and EI. This novel regional contribution identifies diversity between African countries and regions for entrepreneurial actvities and its drivers, with several groups identified. This highlights a requirement for future research encompassing further countries and regions in African, and also multi-year studies that can track these issues longitudinally. The study informs knowledge and practice regarding entrepreneurial behaviour across African regions. Through examination of the different combinations of condition variables, across causal recipes, it provides understanding of variations in the socio-cultural drivers of entrepreneurial activity between regions, groups of regions, and countries, for TEA and EI.
\end{abstract}

Keywords

Africa, Regions, Entrpreneurial Activity, Entrepreneurial Intention, FsQCA 


\section{Introduction}

Dana ands Ratten (2017) note Africa is a key global economy comprising $20 \%$ of the total global land mass and a population of over one billion with many diverse cultures and ethnoheterogeneity (Edoho, 2015a). African nations have recognised the need to encourage entrepreneurial behaviour as a means to encourage economic growth and employment (Garba, 2010). Nafukho and Muyia (2010) suggests that entrepreneurship, in the African context, has existed in some form since time immemorial. However, despite the massive land mass and population, Africa is inhibited by significant areas of poverty and low average income (Mudamburi, 2012). Published research on entrepreneurial activity within Africa remains nascent in comparison with developed economies (Sheriff and Muffatto, 2015) and is often limited to publication in national journals (Jones et al., 2018a). Moreover, Dana and Ratten (2017) note that entrepreneurial behaviour knowledge is nascent in landlocked African countries like Botswana, Zambia, and Zimbabwe. The African continent is extremely diverse with a population of over 1.2 billion individuals within 54 countries with different political structures and resources (Worldometers, 2017). This includes a significant proportion of low income people, with approximately half of the world's poorest individuals resident in Africa (Khavul et al., 2009). Africa also contains signficiant linguistic diversity that influences culture and business opportunities, George et al. (2016), noting that $25 \%$ of all global languages are spoken in Africa alone, as well as over half the population are under the age of 25.

Despite being resource rich (Dana and Ratten, 2017) regions across Africa suffer from lower rates of effective entrepreneurial activity (Kshetri, 2011). There are several underlying reasons for this as summarised recently by Jones et al., (2018a) and Ratten and Jones (2018). First, ineffective infrastructure in terms of unreliable electricity, water supply, and inadequate road, rail, sea and air transport networks is endemic in African countries particularly in rural regions (Atiase et al., 2017). Secondly, rural regions suffer from a talent drain, whereby people migrate to cities seeking improved employment oportunities, creating limited economy activity in rural areas beyond basic agriculture and infrastructural overload in the major cities caused by road gridlock due to people migration (Misago, 2016). Further, many African countries suffer from excessive administration processes and excessive tax systems that impact negatively upon the small business sector, encouraging start-up and entrepreneurial spirit (Robson et al., 2009).

Whilst countries and regions within Africa are currently experiencing significant growth in contrast to innovation driven economies, there is also a recognition that for entrepreneurial activity to be encouraged, national and regional eco-systems need to be established between businesses, policy makers, enteprise support agencies and educational institutions (Amaeshi and Idemudia, 2015). Economies within the African continent are also impacted by global trends such as globalisation and increased technological sophistication. There are emergent examples of emergent entrepreneurial activity, for example the film and television industry in Nigeria (Madichie et al., 2019). It is important, therefore, to attempt to understand the conditions existing within African regions which may support or mitigate entrprenerurial activity.

The primary technique employed in this study is fuzzy-set Qualitative Comparative Analysis (fsQCA) (Ragin, 2008; Kraus et al., 2018). Its employment is pertinent since it is able to operate on small $n$ data (here African regions), as well as offering both multi-conjunctural and 
asymmatric aspects to its analysis (ibid.). To the authors' knowledge this is the first Afrcian region level study analysed using fsQCA.

Whilst studies such as Ács et al. (2012) identify small and medium enterprises (SMEs) in developed economy contexts as supporting innovation-focused economies and creating innovation, employment and growth, Van Stel et al. (2005) argues that entrepreneurship plays differing roles in economies at different stages of development. This is related to individuals undertaking entrepreneurship to exploit opportunity or out of necessity (Tominc \& Rebernik, 2007), the mix of opportunity and necessity entrepreneurship itself affected by the stage of economic development. Wennekers et al. (2005) identifies a U-shaped relationship exising between entrepreneurship and economic development. In developing, factor-driven economies, more strongly characterised by necessity-based entrepreneurship, total entrepreneurship activity tends to be high. This then reduces as economies enter the efficiency (manufacturing-dominated) phase as necessity entrepreneurship falls. Entrepreneurship activity, more driven by opportunity then tends to rise again during the services, innovationdriven phase. Ács et al. (2008) suggest, however, that this U-shaped framework may be unsuitable for policymaking. Instead there is a requirement for more context specific analysis able to map the potential alternative combinations of factors that may affect entrepreneurship in different countries and regions.

\section{Entrepreneurship and Africa}

Literature observing entrepreneurship on the African continent is less prominent or effectively reported (Jones et al., 2018a). There is recognition for the need for effective entrepreneurial behaviour to ease a myriad of systemic problems including high graduate unemployment, endemic poverty, economic growth inequality, corruption, excessive bureaucracy, ineffective infrastructure and a lack of effective ecosystems (Lundvall and Lema, 2014; Sutter et al., 2019). Moreover, research into entrepreneurial behaviours remains limited in the complex and heterogeneous African context (Ratten and Jones, 2018). Recently, Jones et al., (2018b) noted the need for increased research on contextualised entrepreneurial behaviour that focuses on different market and industry segments, the behaviour of the entrepreneur involved and outcomes achieved in specific cultural contexts. The extant literature that does exist in an African context remains limited and typically explores behaviour in a single country context (Vermeire and Bruton, 2016). Specifically, studies typically do not account for the diverse nature of many African countries. There is a need, therefore, for further studies to evaluate and contrast entrepreneurial behaviour on a comparative basis (both between countries and regions).

Entrepreneurship research increasingly considers the concept of opportunities (Reynolds et al., 2003), as a fundamental characteristic of entrepreneurship behaviour (Arenius and Minniti, 2005), because inadequate entrepreneurial-activity levels result in deficient opportunities (Krueger et al., 2000). Ács et al. (2008) posit that an individual's perceptions of their environment also either encourages or discourages them towards entrepreneurship both in terms of intention and also actuality. Conversely, fear of entrepreneurship failure prevents individuals from undertaking business start-up because many individuals are risk adverse (Vaillant and Lafuente, 2007). Underlying national, regional, cultural, and economic development-level characteristics may also affect these variables, such as the individual's 
confidence in their own potential as an entrepreneur (McGee et al., 2009), their awareness of entrepreneurs in their own local economic environment (Amo, 2013; Abu Bakar et al., 2017), and education levels (Amo, 2013; Dickson et al., 2008).

The Global Entrepreneurship Monitor (GEM) survey is useful to research entrepreneurial activity and entrepreneurial attitudes and perceptions (EAaPs) in various country settings (U1 Haq et al., 2014). Specifically, this study considers EAaPs, as defined by Bosma et al. (2012), in an African regional context and their association with Entrepreneurial Activity (TEA) and also Entrepreneurial Intention (EI), using the GEM (2013) dataset (Bosma et al., 2012) on an fsQCA analysis across 59 African regions in seven countries.

\section{Methodology, data and varaiables}

\section{FsQCA}

This analysis employs fuzzy-set Qualitative Comparative Analysis (fsQCA), described in detail in Ragin (2008), a set-theoretic technique for causal-oriented investigation. The technique is a development on the original QCA (Ragin, 1987). It has increasingly been applied in the broad area of entrepreneurship research (see discussion in Kraus et al., 2018). The technique provides the identification of a combination of behavior's (condition variables) required to achieve an outcome (dependent variable).

The review of fsQCA in Kraus et al. (2018), includes the motivation for the employment of this technique in this research, pertinently stating (made up of two quotes):

FsQCA is a diversity-oriented approach which proposes different alternative paths to understand the construct of an outcome and is furthermore well suited for observing stochastic but complex (small-n) phenomena (p. 16)

and

Unlike more quantitative methods which are based on correlation, fsQCA seeks to establish logical connections between the combinations of causal conditions (conjunctural causation) and an outcome, which results in rules that summarize the sufficiency between subsets of all the possible combinations based on their causal conditions (or their complement) and the outcome. (p. 17)

The analysis given in this study demonstrates these traits of fsQCA clearly.

Data

Data for the African region level data analysis was obtained with permission from the GEM consortium for access to the latest national data for the African continent. This included access to individual country level datasets and Sub Saharan Regional Reports in seven countries (Namibia, Ghana, Botswana, South Africa, Uganda, Zambia and Nigeria). The study considers the association between the following variables. 


\section{Condition Variables}

Knowledge of entrepreneurs (KNOWSM): Amo (2013) identified knowledge of other entrepreneurs as related to probability of undertaking start-up activitites, whilst Abu Bakar et al. (2017) identified this in the developing economy context. This is defined here as the percentage of 18-64 age group who know someone personally who started a business in the past two years.

Perceived opportunities (OPPORT): This study draws on Bosma et al.'s (2012) definition of perception of entrepreneurial opportunities: the percentage of 18-64 age group believing that opportunities to undertake business start-up in the area they reside exist. Perceived opportunity can drive opportunity entrepreneurship, generating higher economic growth than necessitydriven enterprises (Ács, 2006).

Perceived capabilities (KSENEW): McGee et al. (2009) identify an established academic literature that classifies the business capabilities effective entrepreneurs require. This is defined here as the percentage of 18-64 age group who believe they have the required skills and knowledge to start a business (Bosma et al., 2012).

Fear of failure (FEARFL): Fear of entrepreneurship failure prevents individuals from undertaking business start-up (Vaillant and Lafuente, 2007), because many are risk adverse (Arenius and Minniti, 2005). This study uses the Bosma et al. (2012) definition of business failure as the percentage of 18-64 age group with positive perceived opportunities who indicate fear of failure prevents them from setting up a business.

Education level (UNEDUC): Amo (2013) and Mbeteh et al., (2019) identified personal education level as important to business start up. Indeed, Robson and Obeng (2008) identified a lack of education was a significant barrier to business success in Ghana. Dickson et al. (2008) also found strong evidence supporting the relationship between general education level and several entrepreneurial success measures, though the links between general education level and choice to become an entrepreneur were more ambiguous, suggesting a need for further research in different contexts. In this study, we use average educational attainment $(0-6$ scale where $0=$ pre-primary and $6=$ post tertiary).

\section{Outcome Variables}

Total Entrepreneurial Activity (TEA): GEM defined as people actively involved in nascent entrepreneurship (i.e., business start-up), plus the business stage directly after start-up (i.e., between 3 and 42 months old). In owning/managing a new firm (Bosma et al., 2012), as a percentage of the adult (i.e., 18-64 years old) population (Wennekers et al., 2005).

Entrepreneurial Intention (EI): Entrepreneurial intentions are the expectation of individuals to undertake business start-up (Bosma et al., 2012). Autio et al. (2001) identify several entrepreneurial intent drivers from planned behaviour theory. Entrepreneurial intent can be personally and socially driven, and measures an economy's favourability towards (necessity and opportunity-driven) entrepreneurship. This study uses the GEM definition, which refers to individuals (excluding those individuals already participating in entrepreneurial activity) intending to start a business within the next three years.

A brief statistical description of the considered variables (condition and outcome) is reported in Table 1. 


\section{See Table 1 HERE}

With two outcome variables separately considered (TEA and EI), the scatterplot shown in Figure 1, offers a visual elucidation of their paired values across the 59 African regions.

\section{SEE FIGURE 1 Here}

In Figure 1, each considered African region is represented by a point, based on their respective TEA ( $x$-axis) and EI ( $y$-axis) values described previously. A visual inspection of the spread of the points across the scatterplot, away from the associated regression line (dashed line), indicates there is noticeable variation across the pairs of outcome values for individual African regions (it is noted the relevant correlation between the two variables is $\mathrm{R}=0.462$, sig. $=0.000$, which acknowledges a strong correlation between the two values). The next section undertakes fsQCA analyses using the same condition variables, separately on the two outcome variables.

\section{Stages of FsQCA}

This section undertakes an fsQCA analysis of the described GEM based Africa region data. The order of the reporting of the analysis, using fsQCA, is as follows (see Ragin, 2008); $i$ ) the calibration of the condition and outcome variable data values to fuzzy membership scores (specific to fsQCA), ii) a discussion on the necessity analyses of each condition variable against the two outcome variables, iii) the elucidation of the associated condition variable configurations based truth-table and consistency results for each outcome variable, and $i v$ ) a concomitant sufficiency analyses of high and low outcome derivatives of the two outcome variables.

\section{Calibration}

Prior to the fsQCA analysis, the interval scaled data values, across the condition and outcome variables, need to be re-calibrated so they are in the form of fuzzy membership scores (Ragin, 2008). That is, each variable is considered over the interpretable domain of 0.000 to 1.000 . The calibration process undertaken here is the Direct method, introduced in Ragin (2007), which evaluates the fuzzy membership score values through the identification of qualitatative anchors and subsequent use of the log-odds transformation.

The qualitative anchors structure a fuzzy set, namely the full non-membership (lower threshold), crossover point, and full membership (upper threshold) (Ragin, 2008), here evaluated using the procedure in Andrews et al. (2016) and Beynon et al. (2016), namely identifying the $5^{\text {th }}$ percentile (lower threshold $-\mathrm{x}^{\perp}$ ), $50^{\text {th }}$ percentile (crossover point $-\mathrm{x}^{\times}$) and $95^{\text {th }}$ percentile (upper threshold $-\mathrm{x}^{\mathrm{T}}$ ) of the constructed probability density functions (pdfs) associated with each variable (condition and outcome), see Figures 2 and 3. 


\section{See Figure 2 Here}

\section{See Figure 3 Here}

Each graph in Figures 2 and 3 represents the calibration details for a single variable (condition and outcome). The solid black lines shown are the associated pdfs for each variable (values on left-hand $y$-axis simply infer area under each pdf line sums to one over their respective domain). The three vertical dotted lines are the respective (left to right), lower threshold $\left(\mathrm{x}^{\perp}\right)$, crossover point $\left(\mathrm{x}^{\times}\right)$and upper threshold $\left(\mathrm{x}^{\mathrm{T}}\right)$ qualitative anchors (as labelled). Also reported over the same domain space as the pdfs shown, based on the evaluated qualitative anchors, are the respective fuzzy membership functions (dashed lines) calibrating the specific vsariable interval scale to a $0.000-1.000$ scale (values on right hand $y$-axis), modelled using the log-odds transform (Ragin, 2007).

It is noted, from Ragin (2008), that the fuzzy membership scores are not probablity values, and instead should be seen simply as transformations of interval scales into degrees of membership in the target set (for example the nearer to the value 1.000 on FEARFL the more truth there is an African region being associated with a fear of failure culture). The evaluated qualitative anchors (their positions shown in Figures 2 and 3) were then re-considered, especially the crossover points for the condition variables in terms of the partitioning of the African regions either side of this anchor value. In each graph in Figures 2 and 3, the points above the graph lines are the actual values from the considered African regions, arrows above partition how many such regions are either side of the respective crossover points. This evidence, and knowledge on the African regions themselves, was considered by experts on African entrepreneurship, enabling discussion on the appropriateness of the evaluated qualitative anchors. It was felt the qualitative anchor points were appropriate in this exploratory study, enabling the specific fuzzy membership scores for each condition and outcome variable to be future considered for the African regions.

\section{Necessity analyses}

This section reports the fsQCA oriented necessity analyses of the calibrated African region data. Following Ragin (2008), this relates to the assessment of the consistency of a set relation indicating that a condition variable is a necessary condition for an outcome. In technical terms, from the fuzzy membership scores describing the 59 African regions, the consistency of the necessary condition relationship depends on the degree to which it can be shown that membership in the outcome is consistently less than or equal to membership in the cause (ibid. -measure of coverage also available). Results need to be considered in respect of each condition variable (Var - presence of condition) and its complement ( Var - absence of condition), the same for the outcome variables (outcome and outcome), see Table 2.

\section{See Table 2 Here}


The necessity based consistency and coverage results in Table 2 indicate no single condition variable (whether Var or $\sim$ Var) is above the often referred to threshold of consistency of 0.900 , Young and Park (2013) (bottom of the table shows the respective min and max values across each of the measures for both TEA and EI). It was deemed no single condition variable (their presence or absence) was necessary for the high or low outcome derivatives of either of the two outcome variables.

\section{Truth table elucidation}

Following the results from the necessity analyses, highlighting no variables necessary for an outcome, this section elucidates the condition variables configuration based truth tables associated with each of the two outcomes (TEA and EI). Ragin (2008, p. 23) succinctly describes the role of truth tables:

\section{"Truth tables list the logically possible combinations of causal conditions and the empirical outcome associated with each configuration."}

Here, with two outcome variables, the adapted truth table presented in Table 3 includes the information as described in the above statement, for both outcomes.

\section{See Table 3 Here}

In Table 3, with five condition variables, there are $2^{5}=32$ different logically possible configurations. The relationship between these configurations (combinations of $0 \mathrm{~s}$ and $1 \mathrm{~s}$ across the different condition variables) and the considered African regions is first based on the notion of strong membership, (for a condition variable a fuzzy membership score either below or above 0.500 is assigned the values 0 and 1 respectively). It is the strong membership form of the African regions condition values that associates them with a configuration (shown in Table 3).

The number column in Table 3 identifies the number of African regions which are most associated with each configuration, in strong membership terms. Inspection of these values notes 11 configurations each have one African region associated with them (e.g. configuration 9 with condition terms 01000 in short form), and at the other end of the scale, configuration 31 (condition values 11101) has 14 African regions associated with it. The accompanying 'African regions (Country)' column to the right shows the actual African regions (and country three letter code it is part of) associated with the configuration (will be referred to later).

This discussion of the groupings of African regions across the possible configurations is important in terms of which configurations to continue to consider. Ragin (2008) discuss this in terms of a frequency threshold, namely the relevance or viability of a configuration. Here, it was decided configurations with at least two African regions associated with them were to 
be continued to be considered. It follows, 11 configurations, each with only one African region (and configurations not shown with zero African regions associated with them) are not considered in terms of the sufficiency analysis, but now termed remainders (respective rows in Table 3 have values striked through), they will be considered in terms of whether they are later compared against.

The final two main columns, each with two subcolumns, elucidate the associated raw consistency values of each configuration to the concomitant high or low outcome derivatives of each of the two outcome variables. Following Ragin (2008), the raw consistency values represent measures of how well linked a configuration is to an outcome (high and low derivatives), consistency thresholds are necessary (for each high and low outcome derivative) to partition which configurations are associated or not associated with them, as Ragin (2008) decribes the threshold as a cut-off value for determining which configurations pass fuzzy settheoretic consistency and which do not.

Here, for an individual outcome variable, the same consistency threshold value is employed on both high and low outcome derivatives, following Andrews et al. (2016), is premised on being the least value in which no configuration is further considered to be associated with both highoutcome and low-outcome separately (in this case). In Table 3, the two consistency threshold values found to be employed are 0.871 for TEA and 0.818 for EI. These values are both above the generally considered acceptable benchmark threshold value of around 0.75 (Ragin, 2008), so considered good in the underlying level of consistency being taken forward in our results. The variation in the employed consistency thresholds, 0.871 and 0.818 , suggest the EI outcome configurations are suffering slightly less consistency across the considered configurations compared to the TEA outcome.

The bottom three rows in Table 3 summarise the frequency threshold (here both $\geq 2$ for TEA and EI), consistency threshold ( 0.871 and 0.818 for TEA and EI), and number of continued to be considered configurations and actual African regions, across the different high and low outcome derivatives of the two outcome variables. For a high or low outcome derivative the number of configurations above the concomitant consistency threshold are shown with the relevant consistency value in bold (number of bold values in a respective consistency column). Combining these bold values by the number African regions most associated with the respective configuration gives the number of African regions shown in the final row of the table.

For two configurations and outcomes, namely configuration 2 (00001) for EI and configuration 29 (11100) for TEA, there are no bold consistency values, instead the pairs of consistency values are italicised. While there are greater than one African region most associated with each of them, the associated consistency values are not large enough for the configurations to be considered associated with a respective outcome (they are below the respective consistency threshold values employed). For the respective outcomes these configurations are also now not continued to be considered (grouped with those termed remainders).

\section{Sufficiency Analysis}

Following the elucidation of the required truth tables for the outcome variables TEA and EI, shown together in Table 3, we now consider the analysis of sufficiency. This form of analysis (sufficiency) looks at examing cases with the same causal conditions to see if they also share 
the same outcome. The measure of consistency in regards to sufficiency is the reverse of that for necessity (Ragin, 2008), hence is the degree to which it can be shown that membership in the cause is consistently less than or equal to membership in the outcome (ibid. - with a measure of coverage also available).

One issue to consider prior to the analysis is how should the remainder configurations should be considered based on either not surpassing either the frequency threshold or consistency threshold values employed (see Table 3 and associated discussion). That is, a sufficiency analysis aims to find the minimal conditions ( 0 s and $1 \mathrm{~s}$ of configurations), which discern those configurations associated with either high or low outcome derivatives of an outcome variable from other configurations. Only discerning against those other configurations still considered in Table 3 is termed the complex solution (avoid using any remainders to simplify truth table), while incorporating the remainders that yields the most parsimonious solutions is termed the parsimonious solution. Following Ragin (2008), both solutions are reported on here, see Table 4 (using an adapted version of the circle notaiotn presented in Ragin and Fiss (2008) and empoyed in Andrews et al. (2016)).

\section{See Table 4 here}

In Table 4, the sufficiency analyses findings on high and low outcome derivatives of the TEA and EI outcome variables are reported. As part of this, the reporting of presence and absence of conditions uses an adapted form of the cricle notation introduced in Ragin and Fiss (2008).

The two main top-row labelled columns discern results separately on the outcome variables TEA and EI. Below these, there is partitioning to report the respective high and low outcome derivatives. For an outcome derivative, the circle notation discerns the presence (solid circles) or absence (clear line circles) of a condition and whether the condition is core (large circle) or peripheral (small circle) within the causal recipes (vertical combination of cricles). This core or peripheral condition issue, comes from whether the condition is included in the parsimonious solution (core) or only the complex solution (peripheral).

The details below these causal recipes gives descriptive measures associated with each casusal recipe (Ragin, 2008); configurations - which configurations are described by the causal recipe, consistency (how consistently a configuration is a subset of the outcome), raw coverage (the extent to which a recipe can explain the outcome) and unique coverage (the proportion of cases that can be explained exclusively by that recipe) (solution consistency and solution coverage measures relate to the respective set of causal recipes across high and low outcome derivatives). The applied details of these sufficiency analyses (causal recipes) are next described.

\section{Discussion of established causal recipes}

This section systematically discusses the established causal recipes reported in Table 4. With two outcome variables considered, TEA and EI, each with high and low outcome derivatives, the order of presentation of results is to consider the high outcome derivatives of both outcome variables, followed by the low outcome derivatives of both outcomes. Further, the primary focus here is on the Parsimonious solutions, so elucidating first the core conditions in each 
causal recipe, before also higlighting the peripheral conditions found through the concomitant complex solution(s).

\section{High-TEA}

For high TEA, two causal recipes were identified in the parsimonious solution (PTO1, PTO2). PTO1 identified the strong presence of knowledge, skill and experience required to start a new business (KSENEW) and educational attainment (UNEDUC). Peripheral conditions found in the complex solution (CTO1) were the presence of knowing someone who has started a business in the past two years (KNOWSM) and the opportunities for starting a business (OPPORT), as well as the absence of fear of failure (FEARFL) (Bosma et al., 2012). This receipe involves one configuration (30) covering 14 African regions. It is notable that this recipe only represented regions in Zambia (nine regions) and Nigeria (five regions). This suggests that both these countries are relatively proficient in providing the environment and eco-systems to support effective entrepreneurial activity suggesting effective policy supporting entrepreneurial activity that could be mirrored by under performing regions.

The second parsimonious recipe (PTO2) identifes a contrasting formula for high TEA, namely the strong presence of knowledge of someone who has started a business (KNOWSM), the fear of failure (FEARFL), peripheral conditions in the complex solution being presence of business opportunities (OPPORT) and the experience required to start a business (KSENEW), and absence of educational attainment. PTO1 also identifies one configuration (31), this time describing two African regions (Brong Ahafo (GHA), Upper West (GHA)), both from Ghana confirming the findings of Robson and Obeng (2008). These regions are predominatly rural with lower levels of economic activity and population. Economic activity in these regions is typically focused on agriculture/agribusiness and more likely necessity forms of entrepreneurship. Thus this recipe suggests a behaviour whereby indiviudals have access to business networks and opportunities for business activity with a knowledge that they must not fail as they are reliant on the income to support their family. Education in this context is likely less important due to the nature of the necessity business activity. In such regions, agriculture/agribusiness industries remain the predominant industries with limited alternatives available.

\section{Low-TEA}

One causal recipe is identified in the parsimonious solution for low TEA (PTN1). In this recipe, the absence of KNOWSM, namely knowledge of someone who had started a business in the past two years was a key issue, with a range of different peripheral conditions identified in the complex solutions (CTN1 - CTN3). This suggests that the lack of access to business support networks (e.g. family and friends) in rural areas which are dependent on necessity type businesses is of central importance in explaining low TEA which agrees with the findings of Robson et al., (2009). Here six configurations (1, 2, 3, 4, 7, 13), are identified comprising regions from Botswana (5), South Africa (7), Namibia (8), Uganda (2) and Ghana (4). It is notable that there is a geographical cluster of neigbouring countries in Botswana, Namibia, and South Africa. These results offer a more nuanced understanding of the instance of low TEA in an African economy context adding to a limited literature (Sheriff and Muffatto, 2015). Currently. several of these countries are struggling economically, Namibia (ranked $126^{\text {th }}$ 
globally by the International Monetary Fund (2017), Botswana (116 $\left.{ }^{\text {th }}\right)$ and Uganda $\left(102^{\text {nd }}\right)$ ). In addition, the South African economy is currently struggling, with political insability causing economic uncertainty and deteriorating global performance (Fowkes et al., 2016). All these countries considered here suffer from significant disparities in their regional wealth. Thus all the regions considered here typically have low levels of TEA, likely due to poor entrepreneruial eco-systems, infrastructure and resources and an over relience on necessity based entrepreneurial activity. A key issue for policy makers in such regions is the provision of viable entreprenerial activity as an alternative to traditional agricultural occupations.

\section{High-EI}

For high entrepreneurial intention one parsimonious receipe is identified (PEO1) involving five separate configurations $(7,13,29,30,31)$ and 29 African regions. Overall, we can also see four complex solution recipes towards attaining high EI (CEO1 - CEO4). Within these we consistently see the strong presence of KSENEW. Thus, individuals must possess the knowledge, skills and experience required to start a business to possess EI. They are mutually inclusive concepts. Examining the individual configurations it is noteworthy to again examine configration 30. This configuration identifies the presence of KNOWSM, OPPORT, KSENEW, UNEDUC and absence of FEARFL. This configuration was specific to Zambia and Nigeria only. Both these nations demonstrated high TEA as well and so it is to be expected that they also record high EI. This evidence suggests that both these countries are demonstrating improved levels of entrepreneurial activity and efficency and have the required behaviours and regional infrastructure.

\section{Low- EI}

Two causal recipes are identified in the Parsimonious solution (PEN1, PEN2). PEN1 describes two configurations $(1,3)$ which comprises regions from Namibia, South Africa and Ghana. The recipe idendifies the strong absence of KSENEW and UNEDUC. So a lack of education and entrepreneurial skills and knowledge leads to low EI for these configurations.

PEN2 describes two configurations $(3,4)$ which consists of regions from Namibia (5), South Africa (6) and Botswana). This recipe identifies the strong presence of FEARFL and absence of KSENEW. This recipe also therefore suggests that the conditions to support effective entrepreneurial behaviour do not currently exist in these regions and therefore action is required by policy makers to alleviate this issue

\section{Conclusions}

This study demonstrates that fsQCA provides a novel method to compare and contrast entrepreneurial performance, relating entrepreneurship to sets of entrepreneurship drivers on a regional basis in the context of Africa. This study represents the first attempt to analyse and contrast entrepreneurial activity in Africa on a regional basis using GEM data drawn from 59 regions and seven African countries. Moreover, this study offers novel comparative insights into under researched African countries such as Botswana and Zambia plus five others in response to the call from Dana and Ratten (2017). The results highlight potential combinations of factors driving entrepreneurial behaviour across a range of African regions. 
Furthermore, the results enable the identification of regions with high and low TEA and EI across several African countries. The results suggests that EI must exist within regions and prosper before regions move towards actual TEA. The results identify countries with high performing regions in terms of TEA include Ghana, Nigeria and Zambia. A wider superset of regions exhibit high EI, including Ghana, Namibia, Nigeria and Zambia, and also Uganda. It is notable that six Ghanian and four Ugandan regions are classified as EI but have not progressed to TEA. It is apparent that several of these regions are geographically peripheral within their countries (e.g. Ashanti, Western, Upper East and Volta), and likely reliant on agricultural and necessity focused entrepreneurial behaviour. This would suggest that, to help transition these regions to high TEA with beneficial effects on the regional economy, might require progressive regional investment to encourage increased economic activity in these areas and counteract population drift towards the major cities. Importantly, the Education variable is highlighed as a key difference between progressing between EI and TEA for many regions. This evidence should encourage higher and further education institutions to provide relevant educational programmes and training to encourage effective entrepreneurial behaviour.

The results presented here also identify the strong degree of heteregeneity across Africa with regards to the entrepreneurial experience in terms of multiple complex solution recipes illustrated. Indeed, there appears to be a full spectrum of experience for the different nations analysed in terms of the results themselves and the consistency of them across their regions. Zambia and Nigeria have both EI and TEA present for the regions included in the analysis, showing consistent national entrepreneurial activity. Ghana generally seems to have a problem with EI turning into TEA, but also has two regions where this is happening and so shows the strongest regional differences in the analysis with regards to TEA. Uganda also has a problem turning EI into TEA, for various reasons identified in the recipes and different regional experiences. Botswana has absent TEA, though for EI no region was able to be included in the analysis for statistical reasons. Namibia has absent TEA and generally absent EI for various reasons identified in the recipes, though considerable regional difference was highlighted given that for three of the nine Namibian regions included in the analysis EI was found to be present, with different complex solution recipes also identified for these three regions. Finally, South Africa has consistently absent EI and TEA indicating a relative absence of national entrepreneurial activity.

Conversely, and importantly for policy, it can be apparent that there is a strong degree of consistency in the core conditions. Specifically, regions with low TEA lack the knowledge of an entrepreneur, whilst for low EI regions the focus on appropriate skills is consistently absent from nearly all the recipes. In order to obtain higher levels of EI specifically, a focus on entrepreneural skills would therefore be key. However, in order to subsequently achieve higher levels of TEA for countries like Zambia and Nigeria, it is education that is then key. This suggests the need for effective entrepreneurship education and ecosystems to support effective business business start-up (Jones et al., 2018a; Mbeteh et al., 2019). For a country like Ghana (or at least for some of its regions), higher knowledge of an entrepreneur appears to be of greater importance.

Given that the analysis identifies many regions with low EI, and more particularly, low TEA, many of the regions are underperforming in terms of actual entrepreneurial activity, supporting Kshetri (2011) for example. In terms of policy, however, there may be a requirement for a 
range of approaches depending on the nation in question, which may combine national and regional level activity. For example, given that all the South African, Botswanan and Namibian regions included in the analysis are identified as under performing in terms of TEA, there would seem to be a requirement for at least some national level governmental action in these cases, to review policy and practice to support effective entrepreneurial activity. Conversely, whilst there are high TEA regions in Uganda and Ghana, they also have underperforming regions (e.g Northern and Volta in Ghana), suggesting the need for more specific customised regional policy solutions. With regards to EI, there also appears to be a greater degree of regional variation within countries.

This research is therefore highly relevant to government decision-makers and GEM. These results could be potentially useful in informing economic policy by identifying the regional groupings of most relevance when comparing TEA and EI performance and drivers. High performing regions have also been identified and potential best practice highlighted. Similarly, regions of low TEA and EI can be evaluated and problems identified. SME Owner/Managers should benefit in terms of receiving tailored training provision from government entrepreneurship support bodies that will ultimately benefit their entrepreneurial proficiency.

The authors acknowledge that this study is based on snapshot single point of time data and further comparative studies are required comparing regions and countries. Several prior studies have queried the accuracy of GEM data although Beynon et al (2019) provide supporting evidence regarding its validity. Further research exploring entrepreneurial behaviour in a regional context is required in a developing world context especially in Africa, Asia and South East Asia to identify patterns and best practice towards TEA. Further analysis is required of alternate variables such as cultural differences between regions and countries given the diversity across the African continent. Exploring this evidence over a longitundinal basis would add to the evidence base and enable further comparison between regions.

\section{References}

Abu Bakar, A.R., Ahmad, S.Z., Wright, N.S., \& Skoko, H. (2017). The propensity to business startup: evidence from Global Entrepreneurship Monitor (GEM) data in Saudi Arabia. Journal of Entrepreneurship in Emerging Economies, 9(3), 263-285.

Ács, Z. (2006). How is entrepreneurship good for economic growth. Innovations, 1(1), 97-107. Ács, Z.J., Desai, S., \& Hessels, J. (2008). Entrepreneurship, economic development and institutions. Small Business Economics, 31(3), 219-234.

Ács, Z., Brooksbank, D., O'Gorman, P.D., \& Terjesen, S. (2012). The knowledge spillover theory of entrepreneurship: An application to foreign direct investment. International Journal of Entrepreneurship and Small Business, 15(2), 237-261.

Amaeshi, K. \& Idemudia, V. (2015) Africapitalism: A managerial idea for business in Africa?, Africa Journal of Management, 1(2), 210-223.

Åmo, B.W. (2013). Linking network, human capital and the extended competence network to business start-up: a multilevel approach. International Journal of Entrepreneurial Venturing, 5(2), 105-119.

Andrews, R., Beynon, M.J., \& McDermott, A.M. (2016). Organizational capability in the public sector: a configurational approach. Journal of Public Administration Research and Theory, 26(2), 239-258. 
Arenius, P., \& Minniti, M. (2005). Perceptual variables and nascent entrepreneurship. Small Business Economics, 24(3), 233-247.

Atiase, V.Y., Mahmood, S., Wang, Y., \& Botchie, D. (2017). Developing entrepreneurship in Africa: investigating critical resource challenges, Journal of Small Business and Enterprise Development, (forthcoming).

Autio, E., Keeley, R., Klofsten, M., Parker, G., \& Hay, M. (2001). Entrepreneurial intent among students in Scandinavia and in the USA. Enterprise and Innovation Management Studies, 2(2), 145-160.

Beynon, M. J., Jones, P., \& Pickernell, D. (2016). Country-based comparison analysis using fsQCA investigating entrepreneurial attitudes and activity. Journal of Business Research, 69(4), 1271-1276.

Beynon, M. J., Jones, P., \& Pickernell, D. (2019) Country-level entrepreneurial attitudes and activity through the years: a panel data analysis using fsQCA. Journal of Business Research, forthcoming.

Bosma, N., Wennekers, S., \& Amorós, J.E. (2012). Global Entrepreneurship Monitor, 2011 Extended Report: Entrepreneurs and Entrepreneurial Employees across the Globe. Global Entrepreneurship Research Association (Retrieved from Global Entrepreneurship Monitor website: http://gemconsortium.org/report).

Dana, L.P., \& Ratten, V. (2017). International entrepreneurship in resource-rich landlocked African countries. Journal of International Entrepreneurship, 15(4), 416-435.

Dickson, P.H., Solomon, G.T., \& Weaver, K.M. (2008). Entrepreneurial selection and success: does education matter? Journal of Small Business and Enterprise Development, 15(2), 239258.

Edoho, F.M. (2015a). Entrepreneurship and socioeconomic development. African Journal of Economic Management Studies, 6(2), 127-147.

Fowkes, D., Loewald, C., \& Marinkov, M. (2016). Inflating our troubles: South Africa's economic performance and the exchange rate. Economic Research Southern Africa, Policy Paper 22.

Garba, A.S. (2010). Refocusing education system towards entrepreneurship development in Nigeria: A tool for poverty reduction, European Journal of Social Sciences, 15(1), 140-150.

George, G., Corbishley, C., Khayesi, J., Haas, M.R., \& Tihanyi, L. (2016). Bringing Africa in: Promising direction for management research, Academy of Management Journal, 39(2), 377393.

International Monetary Fund (2017). World Economic Outlook Database, Available online: http://www.imf.org/external/pubs/ft/weo/2018/01/weodata/index.aspx.

Jones, P., Maas, G., Dobson, S., Newbery, R., Agyapong, D., \& Matlay, H. (2018a). Entrepreneurship in Africa, part 1: Entrepreneurial Dynamics in Africa, Journal of Small Business and Enterprise Development, 25(3), 346-348.

Jones, P., Klapper, R., Ratten, V. \& Fayolle, A. (2018b). Emerging Themes in Entrepreneurial Behaviours, Identities and Contexts Part 1, International Journal of Entrepreneurship and Innovation, 19(4), 233-236.

Khavul, S., Bruton, G.D. \&, Wood, E. (2009). Informal family business in Africa, Entrepreneurship Theory \& Practice, November, 1219-1238. 
Kraus, S., Ribeiro-Soriano, D., \& Schüssler, M. (2018). Fuzzy-set qualitative comparative analysis (fsQCA) in entrepreneurship and innovation research-the rise of a method, International Entrepreneurship and Management Journal, 14(1), 15-33.

Krueger, N., Reilly, M.D., \& Carsrud, A.L. (2000). Competing models of entrepreneurial intentions. Journal of Business Venturing 15(5-6), 411-432.

Kshetri, N. (2011). Institutional and economic foundations of entrepreneurship in Africa: an overview, Journal of Developmental Entrepreneurship, 16(1), 9-35.

Lundvall, B.A. \& Lemaapages, R. (2014). Growth and Structural Change in Africa: Development Strategies for the Learning Economy. African Journal of Science, Technology, Innovation and Development, 6(5), 455-466.

Madichie N.O., Ajakaiye B.O. \& Ratten V. (2019). The Impact of New Media (Digital) and Globalisation on Nollywood. In: Taura N., Bolat E., Madichie N. (eds) Digital Entrepreneurship in Sub-Saharan Africa. Palgrave Studies of Entrepreneurship in Africa. Palgrave Macmillan, Cham. 89-121.

McGee, J., Peterson, M., Mueller, M., \& Sequeira, J. (2009). Self-efficacy: Refining the measure. Entrepreneurship: Theory and Practice, 33(4), 965-988.

Misago, J.P. (2016). Migration and Socio-Economic Development in African Cities: The Dual Challenge to the Aerotropolis Project of South Africa's Ekurhuleni Metropolitan Municipality, Migrating out of Poverty Research Programme Consortium, Working Paper 35, Available online: http://migratingoutofpoverty.dfid.gov.uk/files/file.php?name=wp35-misago-2016migration-and-socio-economic-development-in-african-cities-ekurhuleni.pdf\&site=354.

Mbeteh, A., Pellegrini M.M. \& Mehtap, S. (2019). Unemployment in Africa and Entrepreneurial Education: A Critical Assessment of Entrepreneurship Education Programmes in Sierra Leone, International Journal of Business and Globalisation, 23(3), 420-451.

Mudamburi, T. (2012). Sustainable millennium framework for managing entrepreneurship in developing countries in Africa (Zimbabwe case study). Journal of Global Entrepreneurship, 2(1), 9-18.

Nafukho, F.M. \& Muyia, M.A.H. (2010). Entrepreneurship and socioeconomic development in Africa: A reality or myth?, Journal of European Industrial Training, 34(2), 96-109.

Ragin, C. (1987). The comparative method: Moving beyond qualitative and quantitative methods. Berkeley: University of California.

Ragin, C.C. (2007). Fuzzy sets: Calibration versus measurement. Methodology volume of Oxford handbooks of political science, 2.

Ragin, C.C. (2008). Redesigning social inquiry: Fuzzy sets and beyond. Chicago, IL: University of Chicago Press. 2008.

Ragin, C. C., \& Fiss, P. (2008). Net effects versus configurations: An empirical demonstration. In Redesigning social inquiry: Fuzzy sets and beyond, ed. Charles C. Ragin, 190-212. Chicago, IL: University of Chicago Press.

Ratten, V., \& Jones P. (2018) Bringing Africa into Entrepreneurship Research. In: Dana L.P., Ratten V., Honyenuga B. (Eds.) African Entrepreneurship. Palgrave Studies of Entrepreneurship in Africa. Palgrave Macmillan, Cambridge.

Robson, P.J.A., Haugh, H.M., \& Obeng, B.A. (2009). Entrepreneurship and innovation in Ghana: Enterprising Africa', Small Business Economics, 32(3), 331-350. 
Robson, P.J.A. \& Obeng, B.A. (2008). The Barriers to Growth in Ghana, Small Business Economics, 30(4), 385-403.

Sheriff, M., \& Muffatto, M. (2015). The present state of entrepreneurship ecosystems in selected countries in Africa. African Journal of Economic Management Studies, 6(1), 17-54.

Sutter, C., Bruton, G.D. \& Chen, J. (2019). Entrepreneurship as a solution to extreme poverty a review and future research directions, Journal of Business Venturing, 34(1), 197-214.

Tominc, R., \& Rebernik, M. (2007). Growth aspirations and cultural support for entrepreneurship: A comparison of post-socialist countries. Small Business Economics, 28(2/3), 239-255.

U1 Haq, M.A., Usman, M., Hussain, N., \& Anjam, Z-u-Z. (2014). Entrepreneurial activity in China and Pakistan: A GEM data evidence. Journal of Entrepreneurship in Emerging Economies, 6(2), 179-193.

Vaillant, Y., \& Lafuente, E. (2007). Do different institutional frameworks condition the influence of local fear of failure and entrepreneurial examples over entrepreneurial activity? Entrepreneurship \& Regional Development, 19(4), 313-337.

Van Stel, A., Carree, M., \& Thurik, R. (2005). The effect of entrepreneurial activity on national economic growth. Small Business Economics, 24(3), 311-321.

Vermeire, J. \& Bruton, G.D. (2016). Entrepreneurial opportunities and poverty in sub-Saharan Africa: a review and agenda for the future, Africa Journal of Management, 2(3), 258-280.

Wennekers, S., Van Stel, A., Thurik, R., \& Reynolds, P. (2005). Nascent entrepreneurship and the level of economic development. Small Business Economics, 24(3), 293-309.

Worldometers (2017). Africa Population, http://www.worldometers.info/worldpopulation/africa-population/.

Young, K.L. \& Park, S.H. (2013). Regulatory opportunism: Cross-national patterns in national banking regulatory responses following the global financial crisis, Public Administration, 91(3), 561-581. 
Table 1. Descriptive statistics of considered condition and outcome variables

\begin{tabular}{|c|c|c|c|c|c|}
\hline KNOWSM: Do you know someone personally who started a & N & Min & Max & Mean & Std. Dev. \\
$\begin{array}{c}\text { business in the past 2 years? } \\
\text { OPPORT: In the next six months, will there be good }\end{array}$ & 59 & 88 & 58.56 & 16.932 \\
$\begin{array}{c}\text { opportunities for starting a business in the area where you live? } \\
\text { KSENEW: Do you have the knowledge, skill and experience } \\
\text { required to start a new business }\end{array}$ & 59 & 28 & 95 & 73.81 & 14.701 \\
FEARFL: Would fear of failure would prevent you from & 59 & 9 & 55 & 24.29 & 9.145 \\
$\begin{array}{c}\text { starting a business? } \\
\text { UNEDUC: UN harmonized Average educational attainment }\end{array}$ & 59 & .56 & 3.69 & 2.1639 & .74017 \\
$\begin{array}{c}\text { TEA: Involved in Total Early Stage Entrepreneurial Activity } \\
\text { EI: Are you, alone or with others, expecting to start a new } \\
\text { business, including any type of self-employment, within the } \\
\text { next three years? }\end{array}$ & 59 & .03 & .55 & .2823 & .12091 \\
\hline
\end{tabular}

Figure 1. Scatterplot representation of Africa regions based on outcome variables TEA and EI

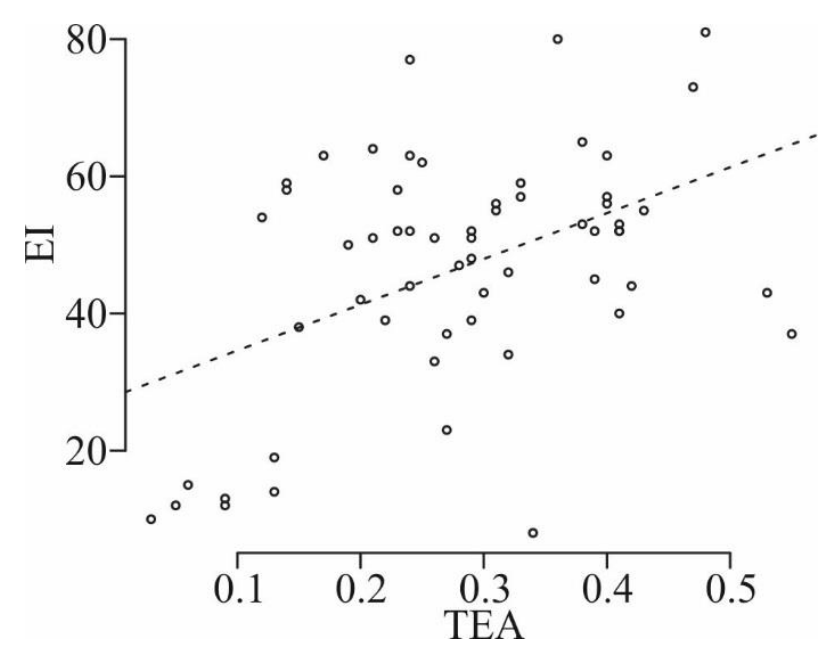


Figure 2. Pdfs of condition variables, showing lower threshold $\left(x^{\perp}\right)$, crossover point $\left(x^{\times}\right)$ and upper threshold $\left(\mathrm{x}^{\mathrm{T}}\right)$ qualitative anchors, and fuzzy membership function graphs

a) KNOWSM

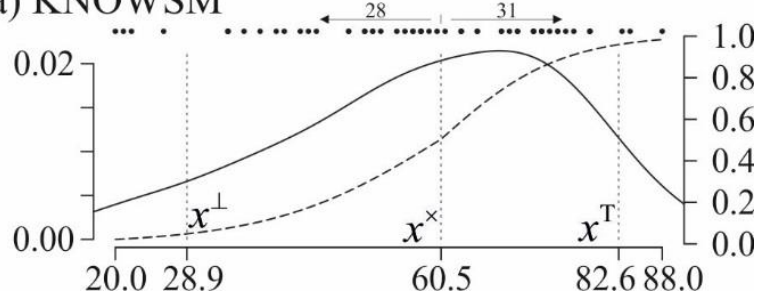

c) KSENEW

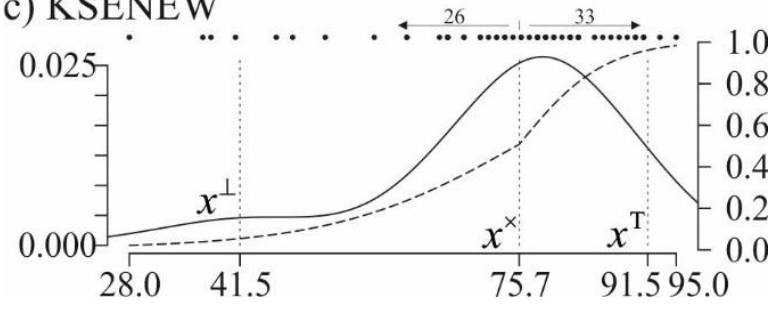

b) OPPORT

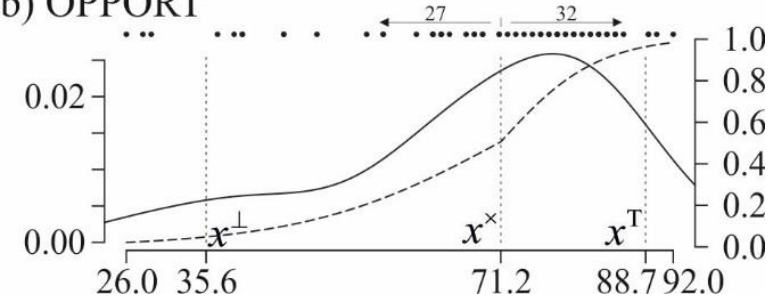

d) FEARFL

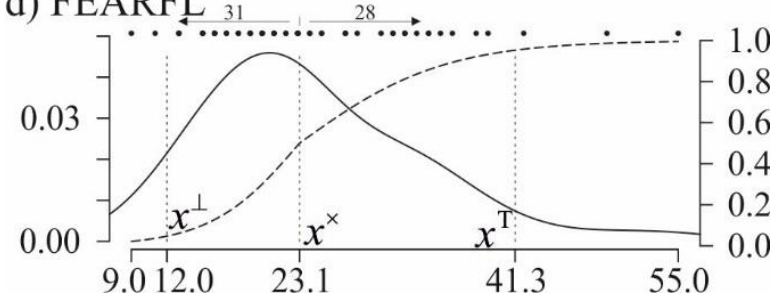

e) UNEDUC

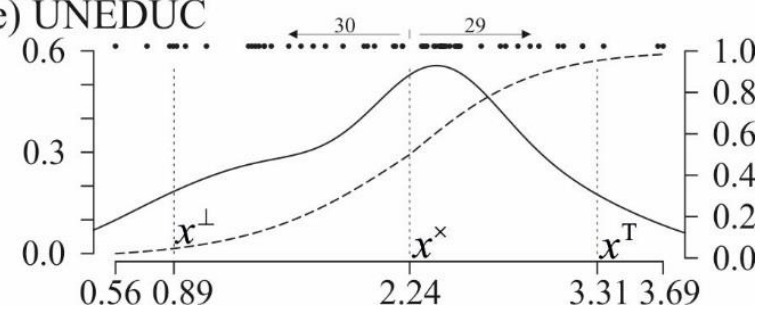

Figure 3. Pdfs of outcome variables, showing lower threshold $\left(x^{\perp}\right)$, crossover point $\left(x^{\times}\right)$ and upper threshold $\left(\mathrm{x}^{\mathrm{T}}\right)$ qualitative anchors, and fuzzy membership function graphs

a) TEA

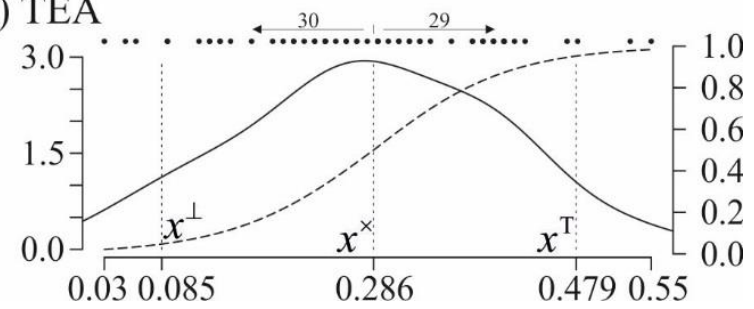

b) EI

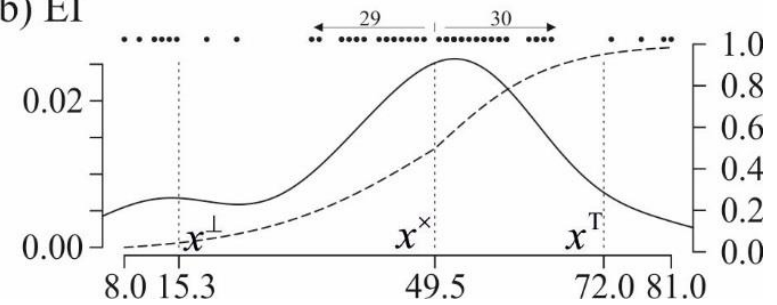


Table 2. Analysis of necessity results for TEA (TEA and TEA) and EI (EI and EI) (Cons - Consistency and Cov - Coverage)

\begin{tabular}{|c|c|c|c|c|c||c|c|c|c|}
\hline Variable & & \multicolumn{4}{|c|}{ TEA } & \multicolumn{4}{|c|}{ EI } \\
\hline (Var) & & \multicolumn{2}{|c|}{ TEA } & \multicolumn{2}{|c|}{$\sim$ TEA } & \multicolumn{2}{|c|}{ EI } & \multicolumn{2}{|c|}{$\sim$ EI } \\
\hline & & Cons & Cov & Cons & Cov & Cons & Cov & Cons & Cov \\
\hline \multirow{2}{*}{ KNOWSM } & Var & 0.854 & 0.823 & 0.518 & 0.502 & 0.707 & 0.694 & 0.667 & 0.634 \\
\cline { 2 - 10 } & $\sim$ Var & 0.484 & 0.500 & 0.818 & 0.849 & 0.628 & 0.660 & 0.679 & 0.692 \\
\hline \multirow{2}{*}{ OPPORT } & Var & 0.864 & 0.783 & 0.564 & 0.514 & 0.757 & 0.699 & 0.658 & 0.588 \\
\cline { 2 - 10 } & $\sim$ Var & 0.463 & 0.514 & 0.762 & 0.849 & 0.554 & 0.626 & 0.663 & 0.726 \\
\hline \multirow{2}{*}{ KSENEW } & Var & 0.849 & 0.764 & 0.608 & 0.550 & 0.757 & 0.695 & 0.709 & 0.630 \\
\cline { 2 - 10 } & $\sim$ Var & 0.501 & 0.559 & 0.740 & 0.831 & 0.597 & 0.680 & 0.656 & 0.724 \\
\hline \multirow{2}{*}{ FEAFL } & Var & 0.588 & 0.622 & 0.629 & 0.668 & 0.617 & 0.665 & 0.636 & 0.664 \\
\cline { 2 - 10 } & $\sim$ Var & 0.686 & 0.647 & 0.644 & 0.611 & 0.688 & 0.661 & 0.678 & 0.632 \\
\hline \multirow{2}{*}{ UNEDUC } & Var & 0.656 & 0.655 & 0.610 & 0.613 & 0.648 & 0.659 & 0.664 & 0.655 \\
\cline { 2 - 10 } & $\sim$ Var & 0.612 & 0.610 & 0.656 & 0.657 & 0.660 & 0.670 & 0.654 & 0.643 \\
\hline \multirow{2}{*}{ Stats } & Min & 0.463 & 0.500 & 0.518 & 0.502 & 0.554 & 0.626 & 0.636 & 0.588 \\
\cline { 2 - 9 } & Max & 0.864 & 0.823 & 0.818 & 0.849 & 0.757 & 0.699 & 0.709 & 0.726 \\
\hline
\end{tabular}


Table 3. All configurations existing from data, based on five condition variables

\begin{tabular}{|c|c|c|c|c|c|c|c|c|c|c|c|}
\hline \multirow{3}{*}{ Configuration* } & \multicolumn{5}{|c|}{ Condition Variables } & \multirow{3}{*}{ Number } & \multirow{3}{*}{ African regions (Country) } & \multicolumn{4}{|c|}{ Raw Consistency Values } \\
\hline & \multirow{2}{*}{\multicolumn{2}{|c|}{ KNOWSM OPPORT }} & \multirow{2}{*}{ KSENEW } & \multirow{2}{*}{ FEARFL } & \multirow{2}{*}{ UNEDUC } & & & \multicolumn{2}{|c|}{ TEA } & \multicolumn{2}{|c|}{ EI } \\
\hline & & & & & & & & High & Low & High & Low \\
\hline 1 & 0 & 0 & 0 & 0 & 0 & 2 & Hardap (NAM), Northern (GHA) & 0.736 & 0.918 & 0.765 & 0.873 \\
\hline 2 & 0 & 0 & 0 & 0 & 1 & 5 & $\begin{array}{l}\text { Gaborone (BWA), Selibe-Phikwe (BWA), Central } \\
\text { (BWA), Kweneng (BWA), Limpop/ Mpuma (ZAF) }\end{array}$ & 0.628 & 0.945 & 0.803 & 0.766 \\
\hline 3 & 0 & 0 & 0 & 1 & 0 & 3 & Oshana (NAM), Oshikoto (NAM), East Cape (ZAF) & 0.742 & 0.899 & 0.786 & 0.852 \\
\hline 4 & 0 & 0 & 0 & 1 & 1 & 9 & $\begin{array}{c}\text { Francistown (BWA), Caprivi (NAM), Karas (NAM), } \\
\text { Khomas (NAM), Western Cape (ZAF), Kwa. Natal } \\
\text { (ZAF), Free State (ZAF), N. West /N. cape (ZAF), } \\
\text { Gauteng (ZAF) }\end{array}$ & 0.603 & 0.929 & 0.717 & $\mathbf{0 . 8 2 5}$ \\
\hline 7 & 0 & 0 & 1 & 1 & 0 & 5 & $\begin{array}{c}\text { Kunene (NAM), Omusati (NAM), Kampala (UGA), } \\
\text { Greater Accra (GHA), Volta (GHA) }\end{array}$ & 0.871 & 0.874 & 0.915 & 0.805 \\
\hline 9 & $\theta$ & 4 & $\theta$ & $\theta$ & $\theta$ & 4 & Southern (BWA) & $\theta .872$ & $\theta .901$ & 0.935 & 0.818 \\
\hline $1 \theta$ & $\theta$ & 4 & $\theta$ & $\theta$ & 4 & 4 & Kgatleng (BWA) & $\theta .833$ & $\theta .922$ & $\theta .983$ & $\theta .773$ \\
\hline 13 & 0 & 1 & 1 & 0 & 0 & 2 & Central (UGA), Ashanti (GHA) & 0.850 & 0.893 & 0.934 & 0.818 \\
\hline 15 & $\theta$ & 4 & 4 & 4 & $\theta$ & 4 & Otjozondjupa (NAM) & $\theta .926$ & $\theta .835$ & 0.959 & $\theta .790$ \\
\hline 16 & $\theta$ & 4 & 4 & 4 & 4 & 4 & Erongo (NAM) & $\theta .914$ & $\theta .876$ & $\theta .975$ & 0.827 \\
\hline 18 & 4 & $\theta$ & $\theta$ & $\theta$ & 4 & 4 & Lobatse (BWA) & $\theta .886$ & $\theta .86 \theta$ & $\theta .975$ & $\theta .853$ \\
\hline 19 & 4 & $\theta$ & $\theta$ & 4 & $\theta$ & 4 & Ohangwena (NAM) & 0.976 & 0.837 & 0.964 & 0.863 \\
\hline 21 & 4 & $\theta$ & 4 & $\theta$ & $\theta$ & 4 & Eastern (GHA) & $\theta .950$ & $\theta .82 \theta$ & $\theta .914$ & $\theta .887$ \\
\hline 22 & 4 & $\theta$ & 4 & $\theta$ & 4 & 4 & Western (ZMB) & 0.955 & $\theta .831$ & $\theta .994$ & 0.869 \\
\hline 25 & 4 & 4 & $\theta$ & $\theta$ & $\theta$ & 4 & North (UGA) & $\theta .948$ & $\theta .774$ & $\theta .931$ & 0.897 \\
\hline 27 & 4 & 4 & $\theta$ & 4 & $\theta$ & 4 & Kavango $(\mathrm{N} A M)$ & 0.955 & 0.749 & 0.958 & 0.809 \\
\hline 29 & 1 & 1 & 1 & 0 & 0 & 6 & $\begin{array}{l}\text { Omaheke (NAM), East (UGA), West (UGA), Western } \\
\text { (GHA), Central (GHA), Upper East (GHA) }\end{array}$ & 0.869 & 0.719 & 0.896 & 0.802 \\
\hline 30 & 1 & 1 & 1 & 0 & 1 & 14 & $\begin{array}{l}\text { Lusaka (ZMB), Copperbelt (ZMB), Northern (ZMB), } \\
\text { Luapala (ZMB), North Western (ZMB), Central (ZMB), } \\
\text { Eastern (ZMB), Southern (ZMB),-Muchinga (ZMB), } \\
\text { North Central (NGA), North West (NGA), South East } \\
\text { (NGA), South South (NGA), South West (NGA) }\end{array}$ & 0.982 & 0.515 & 0.836 & 0.783 \\
\hline 31 & 1 & 1 & 1 & 1 & 0 & 2 & Brong Ahafo (GHA), Upper West (GHA) & 0.915 & 0.740 & 0.910 & 0.793 \\
\hline 32 & 1 & 1 & 1 & 1 & 1 & 1 & North East (NGA) & 0.980 & 0.702 & 0.916 & 0.842 \\
\hline \multicolumn{8}{|c|}{ Frequency Threshold } & \multicolumn{2}{|c|}{$\geq 2$} & \multicolumn{2}{|c|}{$\geq 2$} \\
\hline \multicolumn{8}{|c|}{ Consistency threshold } & \multicolumn{2}{|c|}{$>0.871$} & \multicolumn{2}{|c|}{$>0.818$} \\
\hline
\end{tabular}

${ }^{*}$ Only configurations shown for which one case (African region) exists with it - in terms of strong membership 
Table 4. All configurations existing from data, based on variables five condition variable

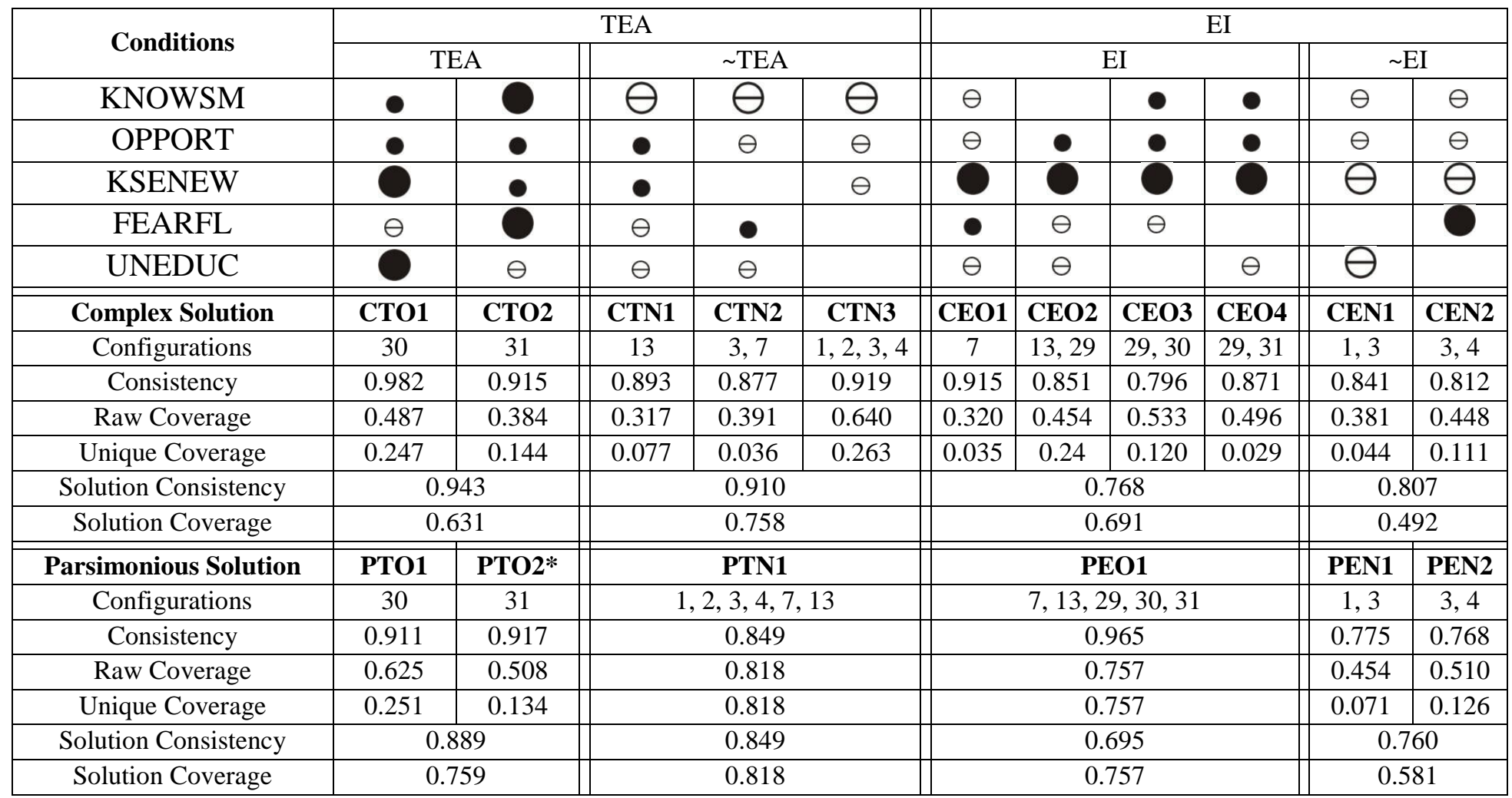

* For this solution there were a number of prime implicants - they were discussed and the one shown is based on the prime implicant with largest solution consistency. 